\title{
Visual Rivalry Without Spatial Conflict
}

\author{
Jeroen J. A. van Boxtel' and Christof Koch ${ }^{1,2}$
}

Psychological Science

23(4) 410-418

(c) The Author(s) 2012

Reprints and permission:

sagepub.com/journalsPermissions.nav

DOI: $10.1177 / 0956797611424165$

http://pss.sagepub.com

'Division of Biology, California Institute of Technology, and ${ }^{2}$ Allen Institute for Brain Science, Seattle, Washington

\begin{abstract}
Visual rivalry has been extensively characterized in the literature. It is thought to require spatial conflict between overlapping visual presentations, even in studies that have found nonspatial (i.e., nonretinal) influences on rivalry. Unexpectedly, we identified visual rivalry in the complete absence of spatial conflict. Participants experienced visual rivalry when we placed a nonambiguous motion stimulus in a nonspatial (in our case, object-based) reference frame. Moreover, a stimulus that was displaced within a nonspatial reference frame did not induce rivalry despite the presence of spatial conflict. This finding shows that nonspatial, object-based processing can overrule retinotopic processing and prevent rivalry from occurring when a perceived stimulus exists unambiguously in an object-based reference frame. Our results identify a potent high-level conflict-resolution stage independent of low-level spatial visual conflict. This independence of spatial overlap provides an advantage to the visual system, allowing conflict resolution when an object is nonstationary on the retina (e.g., during frequently occurring eye movements).
\end{abstract}

\section{Keywords}

rivalry, object based, spatiotopic, retinotopic, ambiguous motion quartet, visual perception, spatial perception

Received 7/8/II; Revision accepted 8/29/II

Visual ambiguities are ubiquitous. Generally, the visual system deals with ambiguity by finding a single "best" solution quite effortlessly. When multiple solutions have an approximately equal likelihood, however, perception may alternate among them (i.e., visual rivalry). Studying visual rivalry gives researchers a means of investigating how the brain forms visual percepts, because such studies uncouple visual stimulation (which remains the same across the experiment) from visual awareness (which fluctuates).

Rivalry can refer both to the visual experience and to the process that underlies this experience. In this article, we will use the term rivalry exclusively for the visual percept (the effect), conflict as a shorthand for the conflicting stimuli (the cause of visual rivalry), and conflict resolution for the mechanism that transforms the visual conflict into visual rivalry (or into an unambiguous percept). We will use the terms spatial conflict, retinal conflict, and retinotopic conflict interchangeably.

To create visual rivalry, researchers construct competing stimuli such that two (or more) possible percepts occupy the same spatial (i.e., retinal) location (e.g., the Necker cube, binocular rivalry). Visual rivalry has been characterized extensively and found to depend on many variables (Alais \& Blake, 2005; Blake \& Logothetis, 2002). One seemingly consistent finding is that visual rivalry requires spatial conflict between overlapping visual presentations (e.g., Blake \& Logothetis, 2002). The dependence of visual rivalry on spatial conflict ties in with the general finding that many forms of rivalry correlate with processing in retinotopic early visual cortex (Haynes, Deichmann, \& Rees, 2005; Polonsky, Blake, Braun, \& Heeger, 2000; Tong \& Engel, 2001; Wunderlich, Schneider, \& Kastner, 2005). Furthermore, what subjects experience in conditions of binocular rivalry relates to the properties of early visual cortex (Blake, 1989). An example is that the size of perceptual dominance zones during binocular rivalry is similar to the size of V1 receptive fields. Some researchers propose that visual rivalry could be dependent on high-level, nonretinotopic brain areas in the fronto-parietal region (Leopold \& Logothetis, 1999; Sterzer \& Kleinschmidt, 2007). In this view, visual rivalry may occur because the brain routinely reinterprets visual information, and this causes perceptual alternations. However, stimuli that have been used to bolster this hypothesis, such as the ambiguous motion quartet (Fig. 1a), involve spatial conflict and have neural correlates in retinotopic early visual cortex, a fact that suggests the critical involvement of early visual processing (Muckli, Kohler, Kriegeskorte, \& Singer, 2005). The apparent dependence of visual rivalry on spatial conflict is in fact one of the most problematic issues for

\section{Corresponding Author:}

Jeroen J. A. van Boxtel, Department of Psychology, University of California, Los Angeles, Franz Hall 6552, Los Angeles, CA 90095

E-mail: j.j.a.vanboxtel@gmail.com 


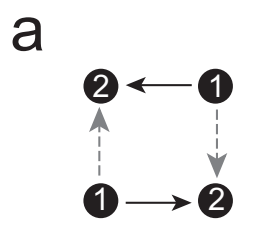

b

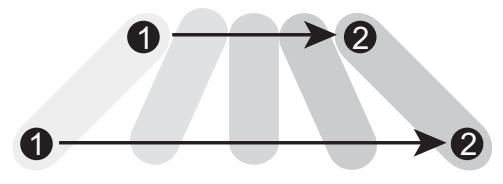

C

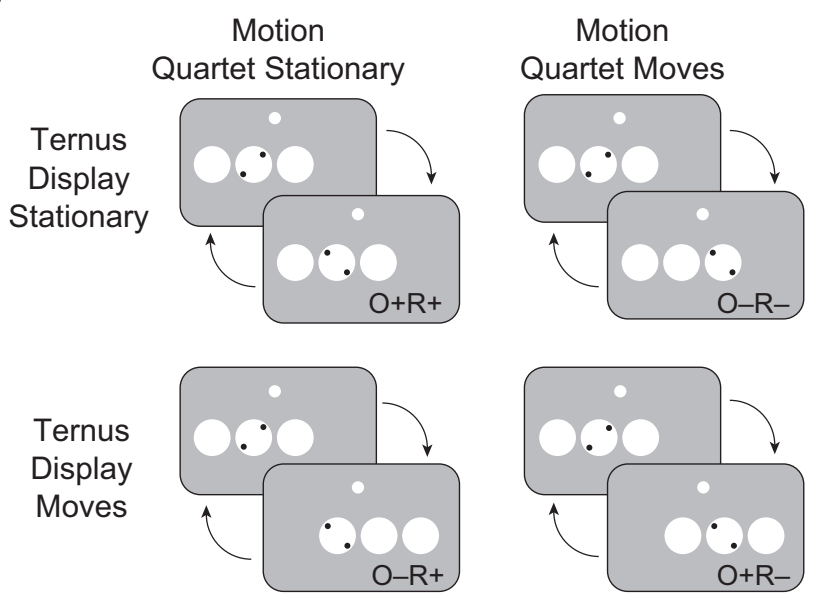

Fig. I. Stimulus layouts and conditions used in the experiments. A traditional ambiguous motion quartet (a) creates spatial conflict using two pairs of dots (marked here as I and 2 for purposes of illustration). The two pairs appear in alternation in a repeated sequence with intervening brief blank intervals. This display may lead to two mutually exclusive percepts: horizontal motion (black arrows) and vertical motion (gray dashed arrows). When the quartet moves back and forth between successive presentations (b), such that the positions of the alternating pairs are separated by several degrees, there is no more spatial conflict, and observers unambiguously perceive a swinging pendulum motion. Both types of motion quartet were combined with a Ternus display (the large white disks; c) to create the four conditions used in the experiments; these conditions were defined by the presence $(+)$ or absence $(-)$ of a retinal $(R)$ or object-based $(O)$ reference frame (see the text for details of the four conditions). The white dot at the top of each image marks the position of the fixation point (which was in the center of the screen during the experiments).

researchers espousing the idea that visual rivalry has a highlevel origin.

Several accounts suggest that potentially nonretinotopic processing stages may influence - but not independently produce-visual rivalry (Blake \& Logothetis, 2002; Tong, Meng, $\&$ Blake, 2006). Such influences include (a) contextual and surrounding information (Andrews \& Lotto, 2004; Bonneh, Cooperman, \& Sagi, 2001; Kovács, Papathomas, Yang, \& Fehér, 1996; Maier, Logothetis, \& Leopold, 2005; van Boxtel, Alais, \& van Ee, 2008; Wilke, Logothetis, \& Leopold, 2003); (b) attention (Meng \& Tong, 2004; Mitchell, Stoner, \& Reynolds, 2004; van Ee, van Dam, \& Brouwer, 2005); (c) muscular, postural, and vestibular information (e.g., Maruya, Yang, \& Blake, 2007; van Boxtel, Wexler, \& Droulez, 2003); and (d) perceptual grouping and surface completion (Bonneh et al., 2001; Graf, Adams, \& Lages, 2002; Maier et al., 2005; Silver \& Logothetis, 2004; Watson, Pearson, \& Clifford, 2004). It is generally assumed that these nonretinal influences take the form of modulatory feedback to conflict-resolution processes at early retinotopic stages (Blake \& Logothetis, 2002; Tong et al., 2006; van Boxtel et al., 2008).

In the study reported here, we investigated whether the visual system employs a nonretinotopic conflict-resolution stage that can produce visual rivalry independently of spatial conflict. Unexpectedly, we found that an object-based reference frame can enable visual rivalry to occur in the absence of spatial conflict. However, visual rivalry was prevented when conflict was absent in an object-based reference frame, despite the presence of spatial conflict. All experiments were undertaken with the understanding and written consent of each subject. Experiments were approved by the institutional review board of the California Institute of Technology and conformed to the Declaration of Helsinki.

\section{Experiment I: Rivalry Without Spatial Overlap}

In Experiment 1, we investigated whether rivalry can occur without spatial conflict. We employed an ambiguous motion quartet to produce visual rivalry (Carter, Konkle, Wang, Hayward, \& Moore, 2008; Hock, Schoner, \& Hochstein, 1996; Muckli et al., 2005; Ramachandran \& Anstis, 1983; Sterzer \& Kleinschmidt, 2007). Conventionally, ambiguity in a motion quartet is created by two pairs of dots that appear to exchange positions on consecutive presentations (Fig. 1a); this induces an illusion of motion that can be perceived as either horizontal or vertical. This stimulus reliably produces the key hallmarks of visual rivalry: exclusivity, inevitability, and randomness (Leopold \& Logothetis, 1999).

\section{Method}

Participants. Seven subjects (4 male, 3 female; age $=18-30$ years) including the first author participated in Experiment 1. All except the first author were naive to the purpose of the experiment, and all had normal or corrected-to-normal vision.

Design and procedure. The ambiguous motion quartet was formed by four black dots (dot diameter $\left.=0.55^{\circ}, 0.12 \mathrm{~cd} / \mathrm{m}^{2}\right)$. The dots formed the edges of a square with sides $2.1^{\circ}$ long. Dot pairs were presented for $173 \mathrm{~ms}$, followed by a $173-\mathrm{ms}$ interstimulus interval.

To investigate whether nonretinal rivalry can occur, we presented the motion quartet in two different spatiotemporal layouts. In the first layout, the motion quartet was repeatedly presented at a single location (as is traditionally done, Fig. 1a). We devised a second layout that was very similar to the conventional one, but which did not contain spatial conflict and thus did not produce rivalry. This was achieved by sequentially presenting the motion quartet at spatially separated locations on alternate presentations (Fig. 1b). This second (i.e., displacement) condition led to an unambiguous (nonrivalrous) 
perception of dots moving horizontally relative to each other, similar to the motion of a swinging pendulum. We then asked whether providing a nonretinal reference frame within which the motion quartet is stationary could reinstate rivalry despite the absence of spatial conflict.

The nonretinal reference frame was created using a moving Ternus display consisting of three white disks (disk diameter $=$ $4^{\circ}, 98 \mathrm{~cd} / \mathrm{m}^{2}$ ) spaced $4.2^{\circ}$ apart. The two central disks were placed symmetrically around the visual midline. The Ternus display appeared and disappeared in a cycle that was synchronous with the appearance and disappearance of the motion quartet. When the Ternus display was displaced, the step size was $4.2^{\circ}$, such that there was always a disk on either side of the vertical midline. The center of each central disk was positioned $4.2^{\circ}$ to the left or right of the visual midline, below a white fixation dot in the center of the screen (Fig. 1c). Background luminance was $49 \mathrm{~cd} / \mathrm{m}^{2}$. Ternus displays are known to provide an effective object-based reference frame for motion stimuli (Boi, Öğmen, Krummenacher, Otto, \& Herzog, 2009; Fig. 1c). The Ternus display allows for either group- or element-motion perception (see examples in Fig. 4a), depending on its design. In Experiment 1, the Ternus display was designed to exclusively allow perception of group motion (He \& Ooi, 1999; Pantle \& Picciano, 1976).

The motion quartet was horizontally aligned to the center of the Ternus display. The displacement of the Ternus display and the motion quartet were determined independently to investigate whether visual rivalry created by motion quartets is dependent on retinal or object-based processing. This procedure resulted in four conditions (Fig. 1c), which were defined by the presence $(+)$ or absence $(-)$ of a retinal $(\mathrm{R})$ or object-based $(\mathrm{O})$ reference frame. In the $\mathrm{O}+\mathrm{R}+$ condition, both object-based and retinal reference frames were present (i.e., the Ternus display and motion quartet were stationary). The effect of this display was essentially equivalent to the effect of a conventional ambiguous motion quartet. In the $\mathrm{O}-\mathrm{R}-$ condition, there was no conflict in either the retinal or object-based reference frames (i.e., the motion quartet was displaced, but the Ternus display was stationary relative to fixation). In the $\mathrm{O}+\mathrm{R}-$ condition, the stimulus contained no retinal conflict, but there was conflicting motion information in the object-based reference frame (i.e., both the Ternus display and motion quartet were displaced). In the $\mathrm{O}-\mathrm{R}+$ condition, the stimulus contained conflict in the retinal reference frame (as in conventional ambiguous motion quartets), but because the motion quartet was moving in the object-based reference frame, the conflict in this reference frame was essentially removed. In this stimulus, the Ternus display was displaced, but the motion quartet was stationary.

Without an object-based reference frame, a horizontally displaced motion quartet is perceived as having only a horizontal, pendulum-like motion. Adding the horizontally moving Ternus display adds more horizontal motion energy and should therefore only strengthen the horizontal perceptual bias. On the basis of motion information alone, we would therefore not expect to find visual rivalry in the $\mathrm{O}+\mathrm{R}-$ condition. If rivalry does occur in this condition, this would show that the nonspatial reference frame provided by the Ternus display reinstates visual rivalry.

Trials lasted $3 \mathrm{~min}$, and each condition was run at least twice per subject. Trials were randomly interleaved. Subjects pressed one of two buttons to indicate whether they saw horizontal motion or vertical motion, respectively; subjects held the button for as long as a percept lasted. Subjects were instructed not to press any button when the percept was unclear to them.

Visual rivalry ideally results in clear percepts that are balanced equally between the two competing stimuli. Therefore, we defined perceptual clarity as the total time either of the two buttons was pressed divided by total trial length, and we defined perceptual bias as the duration of the vertical percept divided by the sum of the duration of the vertical percept and the duration of the horizontal percept. In the case of clarity, 1 indicates ideal visual rivalry. In the case of bias, .5 would be the ideal of visual rivalry. When the motion quartet was moved horizontally between successive presentations, the default unambiguous percept was that of horizontal motion (perceptual bias $=0$ in our definition). Therefore, when the objectbased reference frame was presented, any bias away from zero was a strong indication of object-based processing that causes visual rivalry.

\section{Results and discussion}

Figure 2a shows the results of Experiment 1 in terms of perceptual bias and perceptual clarity. We performed a two-way repeated measures analysis of variance (ANOVA) on perceptual clarity, with motion-quartet displacement (no displacement, displacement) and Ternus-display displacement (no displacement, displacement) as independent factors. This ANOVA showed no significant main effects - both $F \mathrm{~s}(1,6)<1$, $p>.6$ - but a trend toward a significant interaction, $F(1,6)=$ $3.958, p=.09, \eta_{p}^{2}=.4$. The overall perceptual clarity was high in all conditions, which indicates that subjects could clearly distinguish between the different percepts.

We next analyzed the effects of motion-quartet and Ternusdisplay displacement on perceptual bias (Fig. 2b). A 2 (motionquartet displacement $) \times 2$ (Ternus-display displacement) repeated measures ANOVA showed a significant effect of motion-quartet displacement, $F(1,6)=15.906, p<.01, \eta_{p}{ }^{2}=$ .73 , a nonsignificant effect of Ternus-display motion, $F(1,6)=$ 2.443 , n.s., $\eta_{p}{ }^{2}=.29$, and most important, a strong and significant interaction, $F(1,6)=79.120, p<.0002, \eta_{p}{ }^{2}=.93$. As Figure $2 \mathrm{~b}$ shows, conditions with object-based reference frames $(\mathrm{O}+\mathrm{R}+$ and $\mathrm{O}+\mathrm{R}-)$ yielded perceptual biases farther from 0 than conditions lacking object-centered references frames $(\mathrm{O}-\mathrm{R}+$ and $\mathrm{O}-\mathrm{R}-)$.

A more detailed analysis revealed that when both the Ternus display and the motion quartet were stationary $(\mathrm{O}+\mathrm{R}+$ condition), the average perceptual clarity was high $(M=.97$, $S D=.01$, indicating few mixed percepts), and perceptual bias was not strong $(M=.74, S D=.04)$, being significantly smaller than 1 and larger than 0 , both $t \mathrm{~s}(6)>6.5, p<.001$, Cohen's 

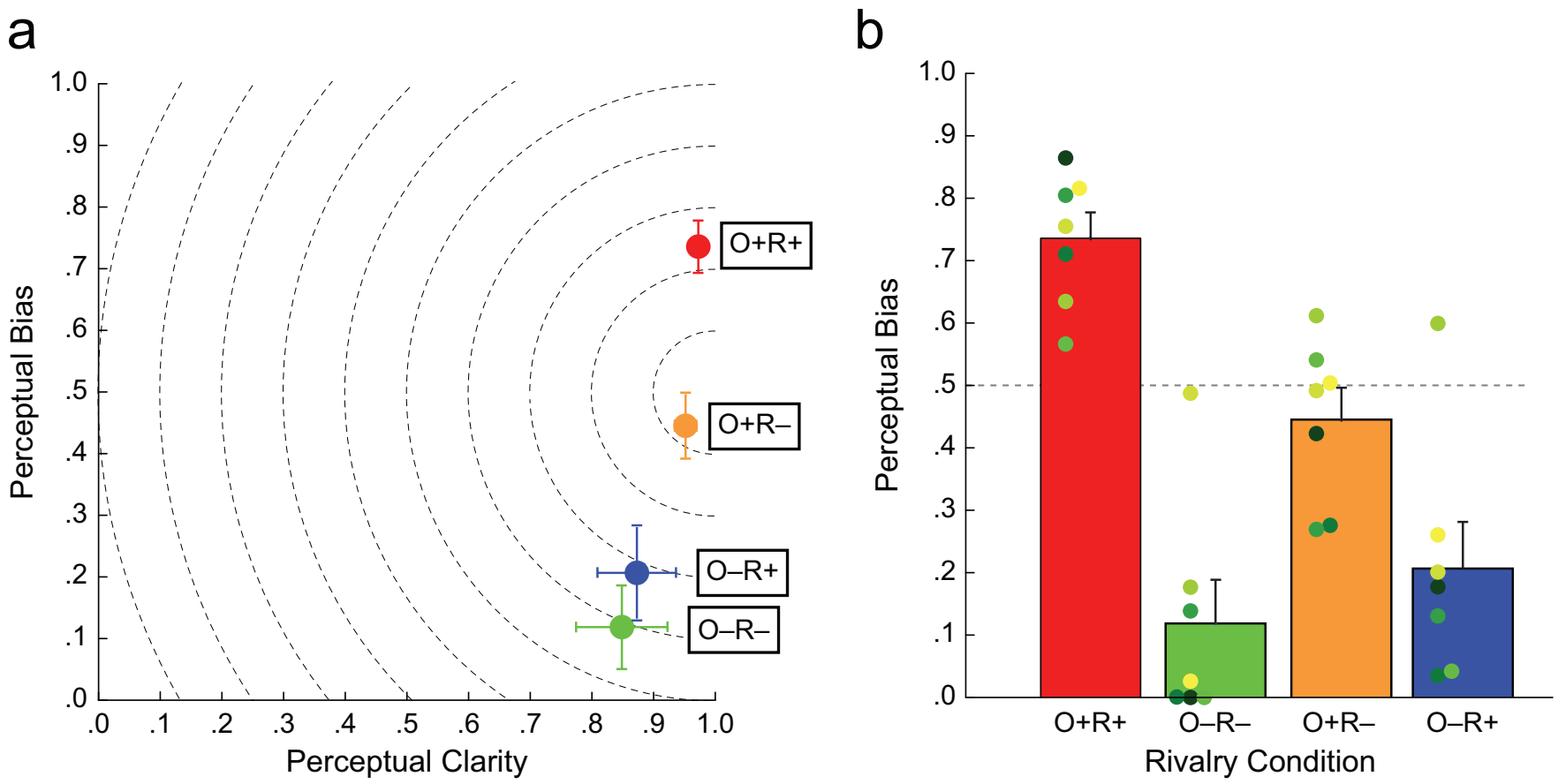

Fig. 2. Results of Experiment I: (a) perceptual bias and perceptual clarity in each of the four conditions and (b) perceptual bias as a function of condition. Perceptual bias was calculated as the duration of the vertical percept divided by the sum of the duration of the vertical percept and the duration of the horizontal percept. Perceptual clarity was calculated as the total time participants pressed either of two response buttons divided by total trial length. In (a), the concentric dashed rings have been added as an aid for readers to visualize distance from the point of ideal rivalry. Error bars show \pm I SEM for both perceptual clarity (horizontal bars) and perceptual bias (vertical bars); for two of the conditions, the error bars for perceptual clarity are too small to be visible in this graph. In (b), the bars show means, and the colored circles indicate results for individual participants. A perceptual clarity of .5 (highlighted by the dashed line) is indicative of ideal visual rivalry, and the error bars show + I SEM. Conditions were defined by the presence $(+)$ or absence $(-)$ of a retinal $(R)$ or object-based $(O)$ reference frame (see the text for details).

$d>2.49$. Together, these results show that visual rivalry is perceived in conventional motion-quartet displays containing spatial conflict, which is in line with previous findings (cf. Carter et al., 2008; Sterzer \& Kleinschmidt, 2007).

The condition with neither retinal nor object-based conflict $(\mathrm{O}-\mathrm{R}-)$ led to a lower perceptual clarity $(M=.85, S D=.07)$ but a very strong bias toward horizontal motion $(M=.12$, $S D=.07)$ The mean perceptual bias was significantly lower than .5 (the level of ideal binocular rivalry), $t(6)=5.66$ (twotailed), $p<.005$, Cohen's $d=2.14$, and not significantly different from $0, t(6)=1.76, p>.1$; subjects described seeing a pendulum-like motion. As expected, this condition showed no visual rivalry.

The critical condition $(\mathrm{O}+\mathrm{R}-)$ provided object-based conflict without retinal conflict by displacing both the motion quartet and the Ternus display. In this condition, perceptual clarity was surprisingly large $(M=.95, S D=.01)$. Perceptual bias was not significantly different from $.5(M=.46, S D=$ $.05), t(6)=1.11, p>.3$, but was significantly larger than 0 and smaller than 1 , both $t \mathrm{~s}(6)>9.00, p<.0005$, Cohen's $d>3.40$, thus indicating visual rivalry.

The final condition $(\mathrm{O}-\mathrm{R}+)$ contained retinal conflict without object-based conflict. This condition yielded a strong bias toward horizontal motion $(M=.21, S D=.07$, which is significantly below .5 ), two-tailed $t(6)=4.05, p<.01$, Cohen's $d=1.53$. The perceptual bias in this condition was not significantly different from perceptual bias in the $\mathrm{O}-\mathrm{R}$ - condition, two-tailed paired $t(6)=1.05, p>.3$, although it was significantly lower than in the $\mathrm{O}+\mathrm{R}+$ and $\mathrm{O}+\mathrm{R}-$ conditions, both $t \mathrm{~s}(6)>4.25, p<.01$, Cohen's $d>1.47$. Note that in the $\mathrm{O}-\mathrm{R}+$ condition, little to no rivalry was observed even though retinal conflict was actually present. This last finding suggests that despite the presence of spatial conflict (which would normally cause rivalry, as in the $\mathrm{O}+\mathrm{R}+$ condition), the absence of conflict in the object-based reference frame prevented visual rivalry; this finding indicates that object-based processing overrules retinal processing.

Our results show that visual rivalry can occur without spatial conflict (as in the $\mathrm{O}+\mathrm{R}-$ condition). Without conflict in the object-based reference frame, there is no rivalry, even in cases when there is conflict in a retinal reference frame (as in the $\mathrm{O}-\mathrm{R}+$ condition). Thus, object-based processing seems to determine whether visual rivalry occurs.

Perceptual clarity and perceptual bias were comparable in the condition without spatial conflict $(\mathrm{O}+\mathrm{R}-)$ and in the condition whose effect was similar to the effect of conventional motion-quartet rivalry $(\mathrm{O}+\mathrm{R}+)$. The similar results in these conditions were further emphasized by the average perceptual 
durations, which were comparable to each other $(M=43.8 \mathrm{~s}$, $S D=13.4 \mathrm{~s}$ and $M=49.8 \mathrm{~s}, S D=10.0 \mathrm{~s}$, respectively), twotailed paired $t(6)=0.57, p>.5$, n.s., and to previous reports of conventional motion-quartet rivalry (Carter et al., 2008). These similarities indicate that object-based rivalry is a genuine form of visual rivalry, and may depend on similar conflict-resolution processes as conventional motion-quartet rivalry does.

\section{Experiment 2: Conventional Motion- Quartet Rivalry and Object-Based Rivalry Are Biased in Similar Ways by Changes in Stimulus Layout}

In Experiment 2, we investigated whether the behavior of object-based rivalry depends on the spatial layout of the motion quartet in the same way as conventional motionquartet rivalry does. In conventional motion-quartet displays, the ratio of the vertical to the horizontal distances between the dots determines the level of perceptual bias; for example, with smaller vertical distances, there is a stronger bias toward vertical motion (Hock et al., 1996). We measured how manipulating these interdot distances affected object-based and conventional rivalry, which should answer whether the two types of rivalry are governed by similar conflict-resolution mechanisms.

\section{Method}

Participants. The same 7 participants from Experiment 1 participated in Experiment 2.

Design and procedure. All procedures and parameters in Experiment 2 were identical to those in Experiment 1, with the exception of the distance between the dots in the motion quartets. There were six conditions, which varied across two parameters. First, the horizontal and vertical distance between the dots in the two pairs varied (vertical distance was greater than horizontal distance, vertical and horizontal distance were equal, and vertical distance was less than horizontal distance). Second, the Ternus display and the motion quartet moved together (object-based conflict; $\mathrm{O}+\mathrm{R}-$ ) or remained stationary $(\mathrm{O}+\mathrm{R}+)$. The distance between the horizontal and vertical dots was $1.26^{\circ}$ and $1.68^{\circ}$, respectively, in the first quartet; $1.68^{\circ}$ and $1.68^{\circ}$, respectively, in the second quartet; and $1.68^{\circ}$ and $1.26^{\circ}$, respectively, in the third quartet (for some subjects, these distances were $1.68^{\circ}$ and $2.18^{\circ}, 2.18^{\circ}$ and $2.18^{\circ}$, and $2.18^{\circ}$ and $1.68^{\circ}$, respectively, in the three quartets). (Data were collapsed across this variation in dot distance.)

\section{Results and discussion}

Object-based rivalry was affected by interdot distance relationships in a manner very similar to conventional motionquartet rivalry (Fig. 3). When the ratio of horizontal over

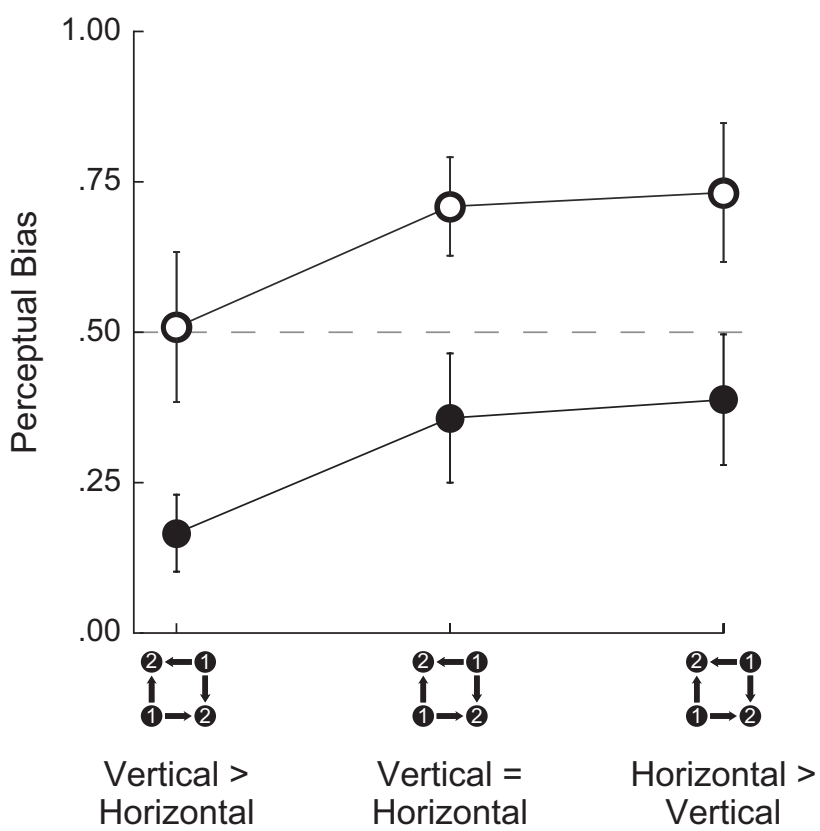

Fig. 3. Results of Experiment 2: perceptual bias as a function of the distance between dots in the motion quartets and the type of rivalry subjects perceived. Subjects saw the Ternus display and the motion quartet either move together (object-based rivalry; black dots) or remain stationary (conventional rivalry; white dots). The distance between the horizontal and vertical dots in the motion quartet varied, such that the vertical distance was greater than the horizontal distance (left), the vertical and horizontal distance were equal (middle), and the vertical distance was less than the horizontal distance (right). (For an explanation of the motion quartets, see Fig. I.) The dashed line shows a perceptual bias indicative of ideal visual rivalry. Error bars show \pm I SEM.

vertical interdot distance was changed from 0.75 to 1.33 , mean perceptual biases increased from $.51(S D=.13)$ to $.73(S D=$ .1) for retinotopic rivalry and from $.17(S D=.06)$ to $.39(S D=$ .11) for object-based rivalry (in both cases, a .22 increase). Indeed, a two-way ANOVA revealed significant main effects of both the Ternus-display motion, $F(1,6)=8.70, p=.026$, $\eta_{p}{ }^{2}=.59$, and the dot configuration, $F(2,12)=4.863, p=.028$,

$\eta_{p}{ }^{2}=.45$, although there was no significant interaction between these two factors, $F<1, p>.8$.

These data show that object-based rivalry can be biased according to well-known perceptual rules previously described for conventional motion-quartet rivalry (Hock et al., 1996), and thus they imply that the two types of rivalry are governed by similar conflict-resolution mechanisms.

\section{Experiment 3: Rivalry Depends on How Stationary the Stimulus Is Perceived to Be in an Object-Based Reference Frame}

Was the object-based rivalry observed in the previous experiments due to the mere presence of a moving Ternus display, or did the Ternus display truly provide an object-based reference 
frame? The Ternus display can be seen as either three disks moving in tandem (i.e., group motion) or as two stationary central disks (relative to the fixation point) plus one disk that jumps from left to right (i.e., element motion; see Fig. 4a). Both conditions contain strong horizontal motion, but only the group-motion display allows for a stable representation of the ambiguous motion quartet in an object-based reference frame. Element motion, on the contrary, does not allow for such a stable representation because the motion quartet is perceived in different disks between displacements.

If visual rivalry occurs both in element and group motion, then the main influence of the Ternus display lies in providing extra horizontal-motion information. If rivalry occurs only with group motion, then conflict in an object-based reference frame is a requirement for motion-quartet rivalry.

\section{Method}

Participants. Six participants from Experiment 1 plus 6 new naive subjects participated in Experiment 3 (overall: 6 female, 10 male; average age $=23$ years).

Design and procedure. There were two conditions in this experiment, which differed in whether participants saw displays inducing perceptions of group motion or element motion. In the group-motion condition, the three disks in the Ternus display were perceived to move in tandem. In the elementmotion condition, the disk on the end was perceived to jump to the other side of the two intervening disks. Parameters in Experiment 3 were identical to $\mathrm{O}+\mathrm{R}-$ in Experiment 1, except that in the element-motion condition, the Ternus display never disappeared. The motion quartet still repeatedly disappeared for $173 \mathrm{~ms}$, and therefore the motion-quartet stimulus was identical in the two conditions and identical to the motionquartet stimuli of Experiment 1.

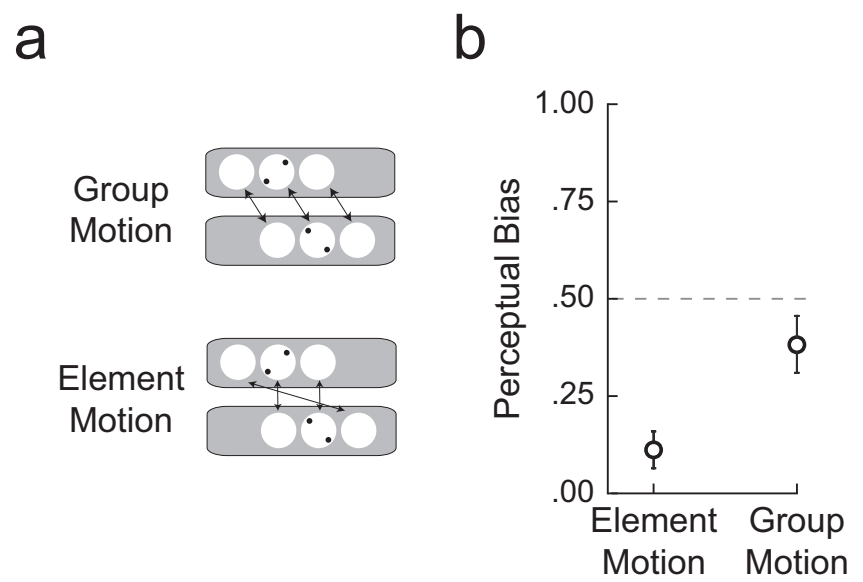

\section{Results and discussion}

Results of Experiment 3 are shown in Figure 4b. In accordance with an object-based rivalry account, the results in the group-motion condition showed a bias that was not significantly different from $.5(M=.38, S D=.07), t(11)=1.6, p>$ .13 , but was significantly different from $0, t(11)=5.15, p<$ .0005 , Cohen's $d=1.49$. The results in the element-motion condition, in contrast, showed a very strong bias toward horizontal motion $(M=.11, S D=.05)$, which was significantly different from .5, $t(11)=8.20, p<.0001$, Cohen's $d=2.36$ ), and therefore showed no rivalry (cf. Fig. $1 \mathrm{~b}$ and results for the $\mathrm{O}-\mathrm{R}-$ condition in Fig. 2b). The difference between both conditions was significant, two-tailed paired $t(11)=3.48, p<$ .006 , Cohen's $d=0.90$. This indicates that the perceptual interpretation of the Ternus display determines whether the motion quartet is perceived as stationary within an objectcentered reference frame and thereby whether rivalry without spatial conflict will occur.

\section{Experiment 4: Rivalry Depends on Object- Based, Not Object-Centered, Processing}

Finally, we investigated whether visual rivalry is object centered or object based. If it is object centered, the coordinate frame that determines whether rivalry is experienced would be defined relative to another object - the Ternus display - that might be anywhere in the visual scene. If it is object based, rivalry would occur only if the rivaling interpretations are perceived to be part of an object (e.g., if they are perceptually linked to the same object). We tested these possibilities by placing the Ternus display below the motion quartet (see Fig. 4c). If rivalry occurred when the motion quartet was perceived to be moving along with the Ternus display, this would indicate that object-centered rivalry had occurred. If no rivalry

C
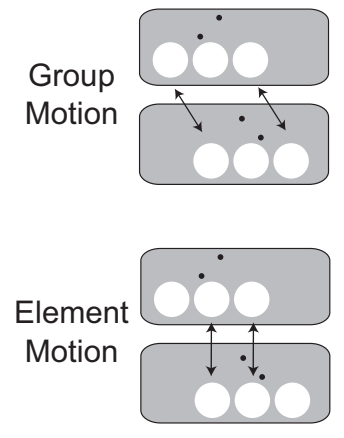

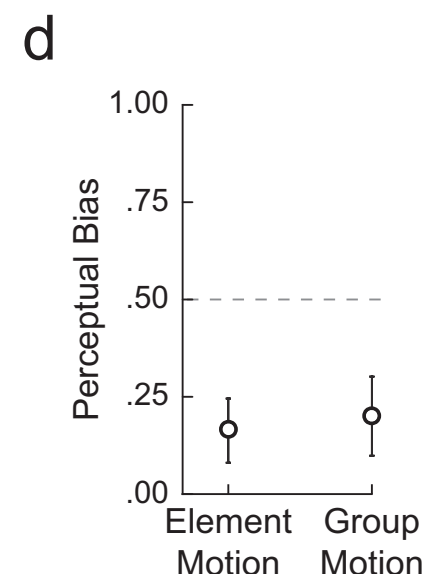

Fig. 4. Conditions and results of Experiments 3 and 4. In Experiment 3 (a), subjects either perceived the three disks in the Ternus display to be moving together in the same order (group-motion condition) or perceived the disk on the end to jump to the other side of the two intervening disks (elementmotion condition). In Experiment 4 (c), the motion of the disks was the same, but the motion quartet appeared above rather than inside the Ternus display. The graphs show perceptual bias as a function of condition in (b) Experiment 3 and (d) Experiment 4 . Error bars show \pm I SEM. 
occurred, this would strongly suggest that the results of Experiments 1 through 3 show instances of object-based rivalry.

\section{Method}

Participants. Six subjects (4 female, 2 male) from Experiment 1 participated in Experiment 4.

Design and procedure. The design and procedure were the same as in Experiment 3, but the Ternus display was presented slightly below the ambiguous motion quartet in the periphery, $8.2^{\circ}$ from the visual midline (i.e., $4^{\circ}$ more peripheral than the motion quartet).

\section{Results and discussion}

Results of Experiment 4 are shown in Figure 4d. When the motion quartet was placed outside of the Ternus display, there was little to no rivalry-group-motion bias: $M=.20, S D=.10$; element-motion bias: $M=.17, S D=.08$-and no significant difference between the two conditions: paired $t$ test, $p>.4$; both data points lie below $.5, t(5)=4.04, p<.05$, Cohen's $d=$ 0.5 , and $t(5)=2.91, p<.02$, Cohen's $d=1.53$. The results of neither condition were significantly different from 0 , both one-sample $t \mathrm{~s}(5)<2.1, p>.1$. These findings indicate that the rivalry does not occur in object-centered coordinates, and they provide evidence that our experimental data are dependent on object-based coordinates.

\section{General Discussion}

In the research reported here, we showed that object-based, nonretinotopic processing causes rivalry when there is no spatial conflict and, conversely, that it may severely hamper rivalry even when conflict is defined in spatial coordinates. Thus, rivalry can occur without spatial conflict. In fact, we identified an object-based processing that is the primary determinant of motion-quartet rivalry. This object-based processing is able to overrule retinotopic processing. Object-based rivalry was similar to conventional motion-quartet rivalry in terms of perceptual clarity, perceptual bias, percept duration, and dependence on stimulus characteristics (Experiments 1 and 2). It occurred even though the object-based reference frame (the Ternus display) added motion energy that should have hampered rivalry (see especially Experiment 3 ).

Previous overviews of the rivalry literature concluded that spatial conflict was necessary for visual rivalry (Blake \& Logothetis, 2002). Indeed, research on visual rivalry always employed spatially overlapping stimuli (Andrews \& Lotto, 2004; Meng \& Tong, 2004; Mitchell et al., 2004; van Boxtel et al., 2008; van Ee et al., 2005). This dependence on spatial conflict was strongly suggested by results of studies that employed rivalry between perceptually completed surfaces (e.g., dot arrays of different colors). When the surfaces were perceptually completed, rivalry ensued, but when the perceptual completion was disturbed - and thereby the spatial overlap between the surfaces ended-rivalry was eliminated (Bonneh et al., 2001; Graf et al., 2002; Kaufman, 1963; Maier et al., 2005; Silver \& Logothetis, 2004; Watson et al., 2004).

Because of the importance of spatial conflict, it has been assumed that nonretinal influences merely modulate the conflictresolution process indirectly through feedback to early retinotopic visual areas (Blake \& Logothetis, 2002; Tong et al., 2006; van Boxtel et al., 2008). Our results instead suggest that rivalry can take place in a nonretinotopic visual stage, independently of retinal conflict. Further, our results show that object-based processing can overrule spatial processing and prevent visual rivalry from occurring when there is no conflict in an object-based reference frame, even in the presence of spatial conflict.

It has been suggested that the visual rivalry in the motion quartet is the result of attention-modulated inference decisions made by fronto-parietal (high-level) brain areas when resolving visual conflict (Leopold \& Logothetis, 1999; Sterzer \& Kleinschmidt, 2007). In higher visual areas, objects are the units of attentional selection (Olson, 2001). Once an object is selected, the processing of the visual scene is largely confined to that specific object. Parts of the scene outside of the selected object are largely ignored. Supporting this idea, we found that the motion quartet had to be perceptually linked to the Ternus display (i.e., the object) in order to cause rivalry. Merely moving the motion quartet along with (and outside of) the Ternus display was not sufficient. This indicates that the rivalry was truly object based (Experiment 4). Consistent with the objectbased nature of the motion-quartet rivalry in our experiment, the findings of a previous study (Mitchell et al., 2004) showed a limited influence of object-based attention in the context of - spatially defined - binocular rivalry over the first approximately $1 \mathrm{~s}$ to $2 \mathrm{~s}$ of stimulus presentation. However, the object-based rivalry we identified in the current study is not dependent on spatial conflict, showing a pure form of objectbased processing that has a potent and long-lasting influence on our visual perception. Moreover, our findings address a problematic issue for hypotheses claiming a high-level origin of rivalry, which was that rivalry seemed to depend on spatial conflict and early visual retinotopic processing. We have now shown that object-based processing, independent of spatial conflict, determines the presence of visual rivalry, which strongly supports high-level accounts of motion-quartet rivalry. These findings mean that our stimulus provides a unique tool to study the high-level, nonretinotopic processes that contribute to visual awareness.

Which brain areas are involved in nonspatial rivalry cannot currently be determined. However, consistent with the idea that fronto-parietal areas are involved in object-based rivalry, previous findings have shown evidence for objectbased processing (Olson, 2001), as well as sensitivity for apparent motion (Sterzer \& Kleinschmidt, 2007; Williams, Elfar, Eskandar, Toth, \& Assad, 2003) in these areas. However, other brain areas may also be involved. For example, 
parts of the ventral visual pathway, the lateral occipital complex and nearby areas, are good candidates because they have been implicated in object-based attention (e.g., O'Craven, Downing, \& Kanwisher, 1999) and motion rivalry (Moutoussis, Keliris, Kourtzi, \& Logothetis, 2005). Furthermore, the ventral visual pathway processes apparent motion (Zhuo et al., 2003).

Because of the lack of spatial conflict during the nonspatial motion-quartet rivalry that we described here, it is unlikely that early visual areas are causally involved (Blake \& Logothetis, 2002; Leopold \& Logothetis, 1999). This observation may not necessarily extend to all types of visual rivalry. Binocular rivalry, for example, has neural correlates in both lower as well as higher visual cortical areas (Haynes et al., 2005; Logothetis \& Schall, 1989; Muckli et al., 2005; Tong \& Engel, 2001; Wunderlich et al., 2005), is dependent on retinal adaptation (Blake, Sobel, \& Gilroy, 2003), and is sensitive to image shifts over the retina (van Dam \& van Ee, 2006), which is not the case for the stimuli we used here. Therefore, binocular rivalry and the nonspatial rivalry we found in the current study may potentially occur at different levels within the visual system.

\section{Conclusion}

Because of the inherently ambiguous nature of visual information, the visual system must allot much of its processing to conflict resolution. Investigations into these processes have used visual conflict between spatially overlapping stimuli, which has led to the idea that spatial conflict is essential to produce rivalry.

We identified a high-level conflict-resolution stage that operates independently of low-level spatial conflict. Studying this mechanism will allow researchers to investigate highlevel contributions to visual awareness without low-level, retinotopic confounds. Because humans make frequent eye movements, having a nonretinotopic, object-based conflictresolution mechanism has advantages over a purely spatial one. It allows the brain to resolve conflict that arises in objects that are nonstationary on the retina through the trans-saccadic processing of visual conflict.

\section{Acknowledgments}

We thank April Kartikasari, Jan Brascamp, David Alais, Michelle To, and Randolph Blake for comments on this manuscript, and Raymond van Ee and David Alais for discussions at early stages of this research.

\section{Declaration of Conflicting Interests}

The authors declared that they had no conflicts of interest with respect to their authorship or the publication of this article.

\section{Funding}

The first author was supported by the Rubicon grant of the Netherlands Society of Scientific Research. Both authors were supported by the National Science Foundation and by the G. Harold \& Leila Y. Mathers Charitable Foundation.

\section{References}

Alais, D., \& Blake, R. (Eds.). (2005). Binocular rivalry. Cambridge, MA: MIT Press.

Andrews, T. J., \& Lotto, R. B. (2004). Fusion and rivalry are dependent on the perceptual meaning of visual stimuli. Current Biology, 14, 418-423.

Blake, R. (1989). A neural theory of binocular rivalry. Psychological Review, 96, 145-167.

Blake, R., \& Logothetis, N. K. (2002). Visual competition. Nature Reviews Neuroscience, 3, 13-21.

Blake, R., Sobel, K. V., \& Gilroy, L. A. (2003). Visual motion retards alternations between conflicting perceptual interpretations. $\mathrm{Neu}$ ron, 39, 869-878.

Boi, M., Öğmen, H., Krummenacher, J., Otto, T. U., \& Herzog, M. H. (2009). A (fascinating) litmus test for human retino- vs. nonretinotopic processing. Journal of Vision, 9(13), Article 5. Retrieved from http://www.journalofvision.org/content/9/13/5

Bonneh, Y. S., Cooperman, A., \& Sagi, D. (2001). Motion-induced blindness in normal observers. Nature, 411, 798-801.

Carter, O., Konkle, T., Wang, Q., Hayward, V., \& Moore, C. (2008). Tactile rivalry demonstrated with an ambiguous apparent-motion quartet. Current Biology, 18, 1050-1054.

Graf, E. W., Adams, W. J., \& Lages, M. (2002). Modulating motioninduced blindness with depth ordering and surface completion. Vision Research, 42, 2731-2735.

Haynes, J.-D., Deichmann, R., \& Rees, G. (2005). Eye-specific effects of binocular rivalry in the human lateral geniculate nucleus. Nature, 438, 496-499.

He, Z. J., \& Ooi, T. L. (1999). Perceptual organization of apparent motion in the Ternus display. Perception, 28, 877-892.

Hock, H. S., Schoner, G., \& Hochstein, S. (1996). Perceptual stability and the selective adaptation of perceived and unperceived motion directions. Vision Research, 36, 3311-3323.

Kaufman, L. (1963). On the spread of suppression and binocular rivalry. Vision Research, 61, 401-415.

Kovács, I., Papathomas, T. V., Yang, M., \& Fehér, Á. (1996). When the brain changes its mind: Interocular grouping during binocular rivalry. Proceedings of the National Academy of Sciences, USA, 93, 15508-15511.

Leopold, D. A., \& Logothetis, N. K. (1999). Multistable phenomena: Changing views in perception. Trends in Cognitive Sciences, 3, 254-264.

Logothetis, N. K., \& Schall, J. D. (1989). Neuronal correlates of subjective visual perception. Science, 245, 761-763.

Maier, A., Logothetis, N. K., \& Leopold, D. A. (2005). Global competition dictates local suppression in pattern rivalry. Journal of Vision, 5(9), Article 2. Retrieved from http://www.journalof vision.org/content $/ 5 / 9 / 2$

Maruya, K., Yang, E., \& Blake, R. (2007). Voluntary action influences visual competition. Psychological Science, 18, 1090-1098.

Meng, M., \& Tong, F. (2004). Can attention selectively bias bistable perception? Differences between binocular rivalry and ambiguous 
figures. Journal of Vision, 4(7), Article 2. Retrieved from http:// www.journalofvision.org/content/4/7/2

Mitchell, J. F., Stoner, G. R., \& Reynolds, J. H. (2004). Object-based attention determines dominance in binocular rivalry. Nature, 429 , $410-413$.

Moutoussis, K., Keliris, G., Kourtzi, Z., \& Logothetis, N. (2005). A binocular rivalry study of motion perception in the human brain. Vision Research, 45, 2231-2243.

Muckli, L., Kohler, A., Kriegeskorte, N., \& Singer, W. (2005). Primary visual cortex activity along the apparent-motion trace reflects illusory perception. PLoS Biology, 3(8), e265. Retrieved from http://www.plosbiology.org/article/info:doi/10.1371/journal .pbio.0030265

O’Craven, K. M., Downing, P. E., \& Kanwisher, N. (1999). fMRI evidence for objects as the units of attentional selection. Nature, 401, 584-587.

Olson, C. R. (2001). Object-based vision and attention in primates. Current Opinion in Neurobiology, 11, 171-179.

Pantle, A., \& Picciano, L. (1976). A multistable movement display: Evidence for two separate motion systems in human vision. Science, 193, 500-502.

Polonsky, A., Blake, R., Braun, J., \& Heeger, D. J. (2000). Neuronal activity in human primary visual cortex correlates with perception during binocular rivalry. Nature Neuroscience, 3, 1153-1159.

Ramachandran, V. S., \& Anstis, S. M. (1983). Perceptual organization in moving patterns. Nature, 304, 529-531.

Silver, M. A., \& Logothetis, N. K. (2004). Grouping and segmentation in binocular rivalry. Vision Research, 44, 1675-1692.

Sterzer, P., \& Kleinschmidt, A. (2007). A neural basis for inference in perceptual ambiguity. Proceedings of the National Academy of Sciences, USA, 104, 323-328.

Tong, F., \& Engel, S. A. (2001). Interocular rivalry revealed in the human cortical blind-spot representation. Nature, 411, 195-199.
Tong, F., Meng, M., \& Blake, R. (2006). Neural bases of binocular rivalry. Trends in Cognitive Sciences, 10, 502-511.

van Boxtel, J. J. A., Alais, D., \& van Ee, R. (2008). Retinotopic and non-retinotopic stimulus encoding in binocular rivalry and the involvement of feedback. Journal of Vision, 8(5), Article 17. Retrieved from http://www.journalofvision.org/ content $/ 8 / 5 / 17$

van Boxtel, J. J. A., Wexler, M., \& Droulez, J. (2003). Perception of plane orientation from self-generated and passively observed optic flow. Journal of Vision, 3(5), Article 1. Retrieved from http://www.journalofvision.org/content/3/5/1

van Dam, L. C., \& van Ee, R. (2006). Retinal image shifts, but not eye movements per se, cause alternations in awareness during binocular rivalry. Journal of Vision, 6(11), Article 3. Retrieved from http://www.journalofvision.org/content/6/11/3

van Ee, R., van Dam, L. C., \& Brouwer, G. J. (2005). Voluntary control and the dynamics of perceptual bi-stability. Vision Research, 45, 41-55.

Watson, T. L., Pearson, J., \& Clifford, C. W. G. (2004). Perceptual grouping of biological motion promotes binocular rivalry. Current Biology, 14, 1670-1674.

Wilke, M., Logothetis, N. K., \& Leopold, D. A. (2003). Generalized flash suppression of salient visual targets. Neuron, 39, 10431052.

Williams, Z. M., Elfar, J. C., Eskandar, E. N., Toth, L. J., \& Assad, J. A. (2003). Parietal activity and the perceived direction of ambiguous apparent motion. Nature Neuroscience, 6, 616-623.

Wunderlich, K., Schneider, K. A., \& Kastner, S. (2005). Neural correlates of binocular rivalry in the human lateral geniculate nucleus. Nature Neuroscience, 8, 1595-1602.

Zhuo, Y., Zhou, T. G., Rao, H. Y., Wang, J. J., Meng, M., Chen, M., ... Chen, L. (2003). Contributions of the visual ventral pathway to long-range apparent motion. Science, 299, 417-420. 